(2) Open Access Full Text Article

\title{
Impact of ghrelin on vitreous cytokine levels in an experimental uveitis model
}

This article was published in the following Dove Press journal:

Drug Design, Development and Therapy

8 January 2013

Number of times this article has been viewed

\author{
Burak Turgut ${ }^{\prime}$ \\ Fatih Cem Gül' \\ Ferda Dağli \\ Nevin Ilhan ${ }^{3}$ \\ Metin Özgen ${ }^{4}$ \\ 'Department of Ophthalmology, \\ School of Medicine, Fırat University, \\ Elazig, ${ }^{2}$ Department of Pathology, \\ School of Medicine, İnönü University, \\ Malatya, ${ }^{3}$ Department of Biochemistry, \\ School of Medicine, Firat University, \\ Elazig, ${ }^{4}$ Department of Rheumatology, \\ School of Medicine, İnönü University, \\ Malatya, Turkey
}

Correspondence: Burak Turgut

Firat University School of Medicine,

Department of Ophthalmology,

Elazığ, Turkey

Tel +904242333555

Fax +904242388096

Email drburakturgut@gmail.com
Background: The purpose of this study was to investigate the effect of intraperitoneal ghrelin on vitreous levels of interleukin (IL)-1, IL-6, and tumor necrosis factor-alpha (TNF- $\alpha$ ) and to compare its effects with those of intraperitoneal infliximab in an experimental uveitis model.

Methods: Twenty-four male rats were assigned to four groups of six rats in each. All the rats, except for those in group 1 (controls), were injected intravitreally with concanavalin A to induce experimental uveitis. Rats in group 2 (sham) were not given any treatment after uveitis was induced. Rats in group 3 were given intraperitoneal infliximab $0.5 \mathrm{mg} / 100 \mathrm{~mL}$ on days 0 , $1,3,5$, and 7 following induction of uveitis on day 14 of the study. Rats in group 4 were given intraperitoneal ghrelin $10 \mathrm{ng} / \mathrm{kg} /$ day for 7 days following induction of uveitis. On day 21 of the study, enucleated globes were subjected to histopathologic examination. Vitreous levels of IL-1, IL-6, and TNF- $\alpha$ were measured by enzyme-linked immunosorbent assay.

Results: Vitreous levels of IL-1, IL-6, and TNF- $\alpha$ were significantly increased in the sham group relative to the control group $(P<0.05)$, but showed a significant decrease in the group treated with infliximab $(P<0.05)$. Cytokine levels also decreased in the ghrelin-treated group, but the decrease was not statistically significant $(P>0.05)$.

Conclusion: Ghrelin failed to decrease the IL-1, IL-6, and TNF- $\alpha$ levels that play a critical role in the pathogenesis of uveitis.

Keywords: uveitis, tumor necrosis factor-alpha, interleukin-1, interleukin-6, infliximab, ghrelin

\section{Introduction}

Uveitis is an inflammatory disease of the uveal tract including the iris, ciliary body, and choroidea. It can lead to permanent damage in various ocular tissues, and eventually to visual loss. Although the exact pathogenesis of uveitis is not clearly described, it is well known that cytokines, which are mediators of immunologic and inflammatory responses, are involved in uveitis. Several cytokines, including interleukin (IL)-1, IL-6, and tumor necrosis factor-alpha (TNF- $\alpha$ ) have been detected in ocular fluids obtained from patients with chronic uveitis. ${ }^{1-3}$

Although an effective treatment modality for uveitis has not yet been introduced, use of anti-TNF agents in uveitis is currently very popular. Infliximab is a mousehuman chimeric monoclonal IgG1 antibody against TNF- $\alpha$. It binds to the TNF- $\alpha$ molecule and reduces production of proinflammatory cytokines, including IL-1, IL-6, and adhesion molecules. It is an agent used in the treatment of disorders such as Crohn's disease, ulcerative colitis, rheumatoid arthritis, ankylosing spondylitis, and uveitis. ${ }^{4}$ Infliximab has also been showed to be efficacious when administered via the 
intravitreal or intraperitoneal route in experimental autoimmune uveitis models. ${ }^{5,6}$

Ghrelin, which was first described by Kojima et al, is a hormone of polypeptide structure, synthesized by many tissues and inflammatory cells, in particular by enteroendocrine cells, like those of the stomach. ${ }^{7-9}$ Ghrelin induces appetite, lipogenesis and secretion of growth hormone, and has antioxidant characteristics. ${ }^{10,11}$ It has been demonstrated that ghrelin inhibits the synthesis of proinflammatory cytokines, including IL-1, IL-6 and TNF- $\alpha$, and that its administration inhibits inflammation in experimental pancreatitis, colitis, acute lung injury, and arthritis models. ${ }^{12-16}$

The aim of the present study was to investigate the effect of intraperitoneal ghrelin treatment on vitreous levels of IL-1, IL-6 and TNF- $\alpha$, and to compare its effects with that of intraperitoneal infliximab in an experimental uveitis model obtained by concanavalin $\mathrm{A}$ in rats.

\section{Materials and methods}

The study included 24 male Lewis rats, of mean weight $300 \mathrm{~g}$. Throughout the study, the rats were kept in the experimental research center at Firat University. The animals were housed in wire-bottomed cages at room temperature on a 12-hour light-dark cycle. All animals were fed with standard rat chow, but were given only water 12 hours before surgery.

The study was carried out on one eye from each animal, with approval from the institutional ethics committee. All procedures were performed with strict adherence to the guidelines for animal care and experimentation prepared by the Association for Research in Vision and Ophthalmology and Guidelines for the Housing of Rats in Scientific Institutions.

\section{Groups}

The rats were randomly allocated to four groups, with six rats in each group. Rats in the groups other than the control group (group 1) were injected intravitreally with concanavalin A (Sigma Chemical Co, St Louis, MO, and ICN Biochemicals, Cleveland, OH) $1 \mathrm{mg} / \mathrm{mL}$ in the right eye only. No uveitis was induced in group 1, nor was any treatment given. Rats in group 2 (sham) were not given any treatment after uveitis was induced. These rats were administered intraperitoneal physiologic serum $2 \mathrm{mg} / \mathrm{kg} /$ day for 2 weeks. Drug administration was started when uveitis-like inflammation developed 2 weeks later. Rats in group 3 were given intraperitoneal infliximab $0.5 \mathrm{mg} / 100 \mathrm{~mL}$ on days $0,1,3,5$, and 7 following induction of uveitis on day 14 of the study. Rats in group 4 were given intraperitoneal ghrelin $10 \mathrm{ng} / \mathrm{kg} /$ day for 7 days following induction of uveitis on day 14 of the study. The rats' eyes were enucleated under analgesia and anesthesia on day 21 . The rats were sacrificed by intracardiac injection of thiopental sodium $50 \mathrm{mg} / \mathrm{kg}$.

\section{Anesthetic technique}

The rats were injected with a combination of intramuscular

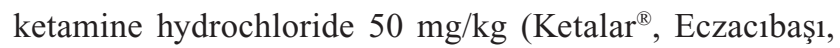
Turkey) and xylazine hydrochloride $5 \mathrm{mg} / \mathrm{kg}$ (Rompun ${ }^{\circledR}$, Bayer, Turkey) to induce anesthesia and analgesia.

\section{Surgical technique}

After induction of anesthesia and analgesia, concanavalin A $1 \mathrm{mg} / 0.1 \mathrm{~mL}$ was injected using a 30-gauge needle into the right eye only, except in the animals in group 1. At the end of the second week, ophthalmoscopy revealed flare in the anterior chamber, moderate cell numbers, fibrin behind the lens, and moderate cataract. After development of uveitis was confirmed clinically, the sham, infliximab, and ghrelin treatment groups were given intraperitoneal injections at the end of the second week, with enucleation of the experimental eyes on day 21 . Vitreous samples were obtained by aspiration using a 27-gauge needle, and sent to the biochemistry laboratory to determine levels of IL-1, IL-6, and TNF- $\alpha$.

\section{Histopathologic methods}

The enucleated eyes were immediately stored in special fixation solution (4\% paraformaldehyde) for 24 hours at $4{ }^{\circ} \mathrm{C}$. They were then transferred into $70 \%$ alcohol and stored at $4^{\circ} \mathrm{C}$ until embedding in paraffin. Sagittal sections $5 \mu \mathrm{m}$ thick were cut and stained with hematoxylin and eosin. For histopathologic evaluation, the iris-ciliary body complex, anterior chamber, vitreous, and retina were observed under light microscopy.

\section{Histopathologic confirmation of experimental uveitis}

Histopathologic examination revealed heavy infiltration of inflammatory cells, edema, and fibrosis in the retina and ciliary body, as well as proliferation in the ciliary epithelium after intravitreal injection of concanavalin A. These signs were interpreted as evidence of induction of uveitis (sham group). None of these histopathologic changes were observed in the control group. Histopathologic examination revealed mild inflammatory cellular infiltration including lymphocytes and rarely eosinophils, edema and fibrosis in the iris and ciliary body in the infliximab-treated group, along with heavy ciliary epithelial proliferation and heavy inflammatory 
cell infiltration, including lymphocytes and eosinophils, and fibrosis in the ghrelin-treated group.

\section{Immunologic evaluation}

Cytokine levels in the vitreous samples were determined for rat IL-1, TNF- $\alpha$ (Invitrogen Corporation, Camarillo, CA), and IL-6 (Ray Biotech Inc, Norcross, GA) using the enzyme-linked immunosorbent assay kits. The measurements were performed using an automated enzyme-linked immunosorbent assay reader (ELX 800, Bio-Tek Instruments Inc, Winooski, VT) at an optic absorbance value of $450 \mathrm{~nm}$.

\section{Statistical analyses}

The means ( \pm standard deviations) of the data obtained were calculated. The statistical analysis was carried out using the Statistical Package for Social Sciences version 13 (SPSS Inc, Chicago, IL). Analysis of variance was carried out for multiple comparisons using the Kruskal-Wallis test, and the Mann-Whitney $U$ test was used for dual comparisons between groups. A $P$ value $<0.05$ was accepted as being statistically significant.

\section{Results}

Table 1 shows the mean TNF- $\alpha$, IL-1, and IL- 6 levels for all the groups. Comparison of the groups showed that the TNF- $\alpha$ levels were higher in the sham-treated eyes than in controls $(P<0.05)$. The mean TNF- $\alpha$ level in the infliximab-treated group was significantly lower than that in the sham group $(P<0.05)$. The mean TNF- $\alpha$ level in the ghrelin-treated group was lower than in the sham group, but not significantly so $(P>0.05)$.

Comparison of the study groups showed that the mean IL-1 level in the sham group was higher than that in the control group $(P<0.05)$. The mean IL-1 level in the infliximab-treated group was significantly lower than that in the sham group $(P<0.05)$. The ghrelin-treated group had a lower IL-1 level than the sham group, but the difference was not statistically significant $(P>0.05)$.

Table I Mean cytokine levels in the study groups

\begin{tabular}{llll}
\hline Groups & TNF- $\alpha(\mathrm{pg} / \mathrm{mL})$ & IL-I $(\mathrm{pg} / \mathrm{mL})$ & IL-6 $(\mathrm{pg} / \mathrm{mL})$ \\
\hline Control & $66.64 \pm 6.91$ & $254.07 \pm 37.07$ & $727.23 \pm 55$ \\
Sham & $88.27 \pm 12.5$ & $316.56 \pm 25.13$ & $902.07 \pm 23.16$ \\
Infliximab & $68.57 \pm 6.4$ & $270.20 \pm 5.27$ & $787.12 \pm 45.40$ \\
Ghrelin & $82.64 \pm 10.31$ & $305.93 \pm 7.5$ & $859.58 \pm 48.40$ \\
\hline
\end{tabular}

Abbreviations: TNF- $\alpha$, tumor necrosis factor alpha; IL-I, interleukin-I, IL-6, interleukin-6.
The mean IL-6 level in the sham group was higher than that in the control group when all groups were compared $(P<0.05)$. The infliximab-treated group had a significantly lower IL-6 level than that in the sham group $(P<0.05)$. The mean IL-6 level in the ghrelin-treated group was lower than that in the sham group, but the decrease was not statistically insignificant $(P>0.05)$.

\section{Discussion}

Uveitis is a disease of the immune system and carries a high risk of severe and permanent visual loss. The exact etiology and pathogenesis of uveitis is not well understood, and there is no effective treatment for the disease as yet. Recent studies performed to find more effective drugs for uveitis and with fewer side effects have yielded variable results. Corticosteroids are among the main drugs used in the treatment of uveitis, and topical, oral, and injectable corticosteroid agents have been widely used in the treatment of intraocular inflammatory conditions since $1956 .{ }^{17}$ However, the side effects that arise with long-term and high-dose administration limit the use of corticosteroids, and have prompted researchers to search for drugs with fewer side effects and greater efficacy. Drugs that act on the immune system can be used in patients whose symptoms cannot be controlled by steroids and who are at high risk for blindness and in cases where the disease is active and involves both eyes. ${ }^{2,17,18}$

Formation of experimental uveitis by intravitreal injection of concanavalin A, retinal-S antigen, rhodopsin, recoverin, and interphotoreceptor binding protein in various experimental studies has contributed to our insight into the etiopathogenesis of human uveitis. ${ }^{19,20}$ In our study, concanavalin A was used to induce uveitis because of its easy availability. Concanavalin $\mathrm{A}$ is a nonspecific inflammatory agent of the lectin group and has a mitogenic effect on $\mathrm{T}$ cells and some B cells. Its intravitreal use has been shown in immunologic studies to cause uveitis. ${ }^{18,19}$ It causes a long-lasting inflammatory response which continues with periods of aggravation and alleviation. Clinically, it is characterized by anterior chamber cells, vitreous cells, development of posterior synechia, and complicated cataract, which are characteristics shown to resemble human uveitis. ${ }^{20}$

In our study, histopathologic examination showed heavy inflammatory cell infiltration, edema, and fibrosis in the retina and ciliary body, as well as proliferation in the ciliary epithelium after intravitreal injection of concanavalin A. These signs were interpreted as evidence of induction of uveitis. None of these histopathologic changes were observed in the control group. 
Although many cytokines are believed to play a part in ocular inflammation, only a few mediators have distinct roles. IL-1, IL-6, and TNF- $\alpha$ are locally and systemically involved in inflammation, so are known as proinflammatory cytokines. The presence of these cytokines has been demonstrated in ocular fluids obtained from patients with acute and chronic uveitis. ${ }^{21-24}$ Because both infliximab and ghrelin affect all three cytokines, these cytokines may be considered as common targets for both drugs. Thus, we preferred to measure the levels of IL-1, IL-6, and TNF- $\alpha$, which play an obvious role in ocular inflammation.

It has been thought that IL-1 may play a key role in development of uveitis, because elevated IL-1 levels are found in patients with active uveitis. ${ }^{25,26}$ The effects of IL-1 resemble those of TNF- $\alpha$. IL-1 specifically affects mononuclear phagocytes and vessel endothelium to increase its further synthesis and stimulate IL-6 synthesis. ${ }^{25-27}$ Hoekzema et $\mathrm{al}^{27}$ argued in their study that the cytokine chain in uveitis might be nothing but a cascade. According to the authors, development of uveitis leads to an increase in TNF, which is followed by involvement of IL-1 and then IL-6. In our study, the IL-1 level in the sham group was found to be significantly higher than that in the control group, which is consistent with previous reports.

IL-6 is involved in the pathogenesis of autoimmune disease, by regulating the immune response, acute phase reactions, and hematopoiesis. It is known that IL-1 and TNF are associated with synthesis of IL- $6 .{ }^{25,26}$ Various studies have found elevated IL-6 levels in uveitis of unknown etiology, pars planitis, systemic diseases associated with uveitis, and viral uveitis. ${ }^{28}$ In our study, we found significantly higher IL-6 levels in the sham group relative to the control group.

TNF- $\alpha$ is a local paracrine and autocrine regulator for low-density leukocyte and endothelium cells. It stimulates mononuclear phagocytes as well as other cell types that produce IL-1, IL-6, and chemokines, and induces migration of polymorphic nuclear leukocytes. TNF- $\alpha$ has a synergistic effect with IL-6, and plays a crucial role in development of inflammation in uveitis. Furthermore, it contributes to the pathogenesis of uveoretinitis associated with Behcet's disease. ${ }^{1,5,6,29}$ We found significantly higher TNF- $\alpha$ levels in the sham group than in the control group.

Infliximab is a human murine monoclonal antibody that can bind to both soluble and transmembranous forms of TNF- $\alpha$ with high affinity. Recently, infliximab has been used as a novel immunomodulatory agent, particularly in uveitis refractory to treatment, panuveitis associated with Behcet's disease, rheumatoid arthritis, and Crohn's disease. ${ }^{28}$
Infliximab was shown to inhibit the functional activity of TNF- $\alpha$ in several in vitro studies. ${ }^{29,30}$ It has been suggested that infliximab exerts its clinical effects in patients with uveitis through various mechanisms, which include reducing serum levels of inflammatory mediators by blocking TNF- $\alpha$, preventing lymphocyte migration, and decreasing levels of vascular endothelial growth factor. ${ }^{31}$ Binding of infliximab to soluble TNF- $\alpha$ brings about a decrease in bioactivity, while its binding to membrane-bound TNF- $\alpha$ results in cytotoxicity through complement-dependent or antibody-dependent cell-mediated mechanisms. However, it is not known how infliximab acts in in vivo models. Secondary to the inhibition of TNF- $\alpha$, infliximab lowers serum levels of inflammatory mediators, including IL-1 and IL- 6 and vascular growth factors. In addition, it reduces lymphocyte migration. ${ }^{29}$ El Shabrawi et al ${ }^{32}$ used an antiTNF- $\alpha$ treatment in recurrent inflammation of the anterior segments in patients with uveitis refractory to standard immunomodulatory therapy. Their study showed that infliximab was highly effective, particularly in patients who had uveitis associated with human leukocyte antigen B27. Patients in their study were observed to stay in remission for a mean of 5.5 months. In another study, Joseph et $a^{33}$ administered infliximab for refractory posterior uveitis due to Behcet's disease or refractory idiopathic posterior uveitis. Attacks of uveitis were suppressed in all patients, and only one patient was observed to develop drug-related side effects. Munoz-Fernandez et $\mathrm{a}^{34}$ used infliximab in combination with methotrexate in panuveitis associated with Behcet's disease and observed a dramatic recovery for ocular inflammation. Smith et $\mathrm{a}^{35}$ compared infliximab and etanercept, both of which are TNF- $\alpha$ inhibitors but via different mechanisms, in patients with uveitis and scleritis associated with rheumatoid disease. They found that inflammation was suppressed in four of 14 patients treated with etanercept and in all patients treated with infliximab. Sartani et $\mathrm{l}^{36}$ administered anti-TNF- $\alpha$ to rats with uveitis induced by interphotoreceptor binding protein and found that development of uveitis was inhibited. We observed at the end of treatment that TNF- $\alpha$, IL-1, and IL-6 levels were significantly reduced in the infliximab-treated group in comparison with the sham group. We also found that infliximab effectively suppressed synthesis of TNF- $\alpha$, IL-1, and IL-6, to levels which were similar to those in the control group, and statistical comparison between infliximab and ghrelin in our study did not detect a significant difference between the groups. These findings demonstrate that infliximab is effective in inhibiting ocular inflammation. 
Ghrelin, a hormone with a lipopeptide structure, is secreted essentially from the stomach fundus, exerts its antiinflammatory activity not only by reducing circulating and tissue levels of IL-1, IL-6, and TNF- $\alpha$ through the growth hormone secretagogue receptor and adenosine, but also indirectly by increasing the cortistatin level. Ghrelin exerts its potent inhibitory effect by reducing mRNA and protein expression via the growth hormone secretagogue receptor. Furthermore, ghrelin inhibits anti-CD3-activated murine $\mathrm{T}$ cells in a dose-dependent manner and production of Th1 and Th2 cells in a nonspecific manner. ${ }^{37-41}$

The effects of ghrelin on the eye have not been fully elucidated as yet. Studies involving rat eyes demonstrated the presence of ghrelin mRNA in the anterior chamber. Rocha-Sousa et $\mathrm{al}^{42}$ found ghrelin in the anterior chamber of the human eye. Ghrelin passes readily across the bloodbrain barrier, which is how passage into ocular tissues takes places. Further, the fact that ghrelin mRNA was detected in a study involving rat eyes suggests that ghrelin may be produced locally in the eye. Katsanos et $\mathrm{al}^{43}$ established in their study that ghrelin levels in the anterior chambers of patients with glaucoma were significantly lower than levels in controls. This finding suggests that ghrelin might have a role in pathologic processes involving the eye. Şehirli et $\mathrm{al}^{44}$ administered intraperitoneal ghrelin $10 \mathrm{ng} / \mathrm{kg} /$ day for one week to rats with skin and distal organ injury following thermal trauma, and demonstrated that TNF- $\alpha$ and IL-6 levels decreased, with resolution of inflammation after treatment. Kasımay et $\mathrm{al}^{45}$ demonstrated in their study that intraperitoneal ghrelin $10 \mathrm{ng} / \mathrm{kg} /$ day administered for one week to rats with induced pancreatitis protected the pancreas and liver against inflammation and reduced IL-1, IL-6, and TNF- $\alpha$ levels. In another study, Erşahin et $\mathrm{al}^{46}$ showed that treatment with ghrelin decreased levels of IL-1, TNF- $\alpha$, and other inflammatory cytokines in rats with induced oxidative brain damage, and exerted a neuroprotective effect. In our study, IL-1, IL-6 and TNF- $\alpha$ levels in the ghrelin-treated group were found to be lower than those in the sham group, but the decrease was not statistically significant.

\section{Conclusion}

We believe that ghrelin administered via the intraperitoneal route may not have penetrated into the eye tissue in adequate concentrations. This may be for several reasons. Because of the blood-retina and blood-aqueous barrier in the eye, only very small quantities of substances enter into the eye tissue. Therefore, ocular penetration of substances remains limited and may not reach the desired levels. Further, the dose we administered may not have reached the concentration required for ocular penetration. In our study, we established that treatment with ghrelin reduced cytokine levels in an experimental uveitis model, albeit not to a statistically significant extent. In the future, further studies including a higher number of cases and using an optimal dose will be needed to find effective doses for local treatment. Measurement of ghrelin levels in ocular fluids might also help to explain why ghrelin was not effective in the present study.

\section{Disclosure}

The authors indicate no financial support or financial conflict of proprietary interest in this work.

\section{References}

1. Franks WA, Limb GA, Stanford MR, et al. Cytokines in human intraocular inflammation. Curr Eye Res. 1992;11:187-191.

2. de Vos AF, Hoekzema R, Kijlstra A. Cytokines and uveitis: a review. Curr Eye Res. 1992;11:581-597.

3. de Vos AF, van Haren MA, Verhagen C, et al. Kinetics of intraocular tumor necrosis factor and interleukin-6 in endotoxin-induced uveitis in the rat. Invest Ophthalmol Vis Sci. 1994;35:1100-1106.

4. Ebert EC. Infliximab and the TNF- $\alpha$ system. Am J Physiol Gastrointest Liver Physiol. 2009;296:612-620.

5. Hosseini H, Safaei A, Khalili MR, et al. Intravitreal infliximab in experimental endotoxin-induced uveitis. Eur J Ophthalmol. 2009;19: 818-823.

6. Demir T, Gödekmerdan A, Balbaba M, et al. The effect of infliximab, cyclosporine A and recombinant IL-10 on vitreous cytokine levels in experimental autoimmune uveitis. Indian J Ophthalmol. 2006;54: 241-245.

7. Kojima M, Hosoda H, Date Y. Ghrelin is a growth-hormone-releasing acylated peptide from stomach. Nature. 1999;402:656-660.

8. Kojima M, Kangawa K. Ghrelin: structure and function. Physiol Rev. 2005;85:495-522.

9. Aydin S, Ozkan Y, Caylak E, et al. Ghrelin and its biochemical functions. Turkiye Klinikleri J Med Sci. 2006;26:272-283.

10. Wren AM, Seal LJ, Cohen MA, et al. Ghrelin enhances appetite and increases food intake in humans. $J$ Clin Endocrinol Metab. 2001;86: 5992-5994.

11. Tschop M, Smiley DL, Heiman ML. Ghrelin induces adiposity in rodents. Nature. 2000;407:908-913.

12. Dixit VD, Pyle RS, Schaffer EM, et al. Ghrelin inhibits leptin-and activation induced proinflammatory cytokine expression by human monocytes and T cells. J Clin Invest. 2004;114:57-66.

13. Dembinski A, Konturek SJ, Ceranowicz P. Ghrelin attenuates the development of acute pancreatitis in rat. J Physiol Pharmacol. 2003;54: 561-573.

14. Mathurin P, Gonzalez F, Kerdraon O, et al. The evolution of severe steatosis after bariatric surgery is related to insulin resistance. Gastroenterology. 2006;130:1617-1624.

15. Chen J, Liu X, Shu Q, et al. Ghrelin attenuates lipopolysaccharideinduced acute lung injury through NO pathway. Med Sci Monit. 2008; 14:141-146.

16. Granado M, Priego T, Martin AI. Anti-inflammatory effect of the ghrelin agonist growth hormone-releasing peptide-2 (GHRP-2) in arthritic rats. Am J Physiol Endocrinol Metab. 2005;288:486-492.

17. Gordon DM. Prednisone and prednisolone in ocular disease. Am J Ophthalmol. 1956;41:593-600.

18. Lightman S. Uveitis: what do we know and how does it help? Clin Experiment Ophthalmol. 2001;29:48-51. 
19. Er H, Uzmez E, Doğan N, et al. The anti-inflammatory effects of nitro $\mathrm{L}$ arginine (L-NAME) and steroid in concanavalin A induced uveitis. J Med Sci. 1999;29:233-239.

20. Gwon A, Mantras C, Gruber L, et al. Concanavalin A-induced posterior subcapsular cataract: a new model of cataractogenesis. Invest Ophthalmol Vis Sci. 1993;34:3483-3488.

21. Roitt I, Male D. Immunology. International Edition, 6th ed. 1998: 234-240.

22. Kijlstra A. The role of cytokines in ocular inflammation. $\mathrm{Br} J$ Ophthalmol. 1994;78:885-886.

23. Abbas AK, Pober JS. Cytokines. Cellular and Molecular Immunology, 3rd ed. Pennsylvania, PA: WB Saunders Company; 1997.

24. Murray PI, Van Haren HR. MAC: aqueous humor interleukin-6 levels in uveitis. Invest Ophthalmol Vis Sci. 1990;31:917-920.

25. Rutanen EM. Cytokines in reproduction. Ann Med. 1993;25: 343-347.

26. Galley HF, Webster NR. The immuno-inflammatory cascade. $B r J$ Anaesth. 1996;77:11-16.

27. Hoekzema R, Murray PI, Kijlstra A. Cytokines and intraocular inflammation. Curr Eye Res. 1990;9:207-211.

28. de Boer JH, Van Haren MA, Baarsma GS, et al. Analysis of IL-6 levels in human vitreous fluid obtained from uveitis patients, patients with proliferative intraocular disorders and eye bank eyes. Curr Eye Res. 1992;11 Suppl:181-186.

29. Murphy CC, Ayliffe WH, Booth A, et al. Tumor necrosis factor alpha blockade with infliximab for refractory uveitis and scleritis. Ophthalmology. 2004;111:352-356.

30. Sfikakis PP, Theodossiadis PG, Katsiari CG, et al. Effect of infliximab on sight-threatening panuveitis in Behcet's disease. Lancet. 2001;35: 295-296.

31. Remicade IV injection [Prescribing information]. Malvern, PA: Centocor; 1999.

32. El-Shabrawi Y, Mangge H, Hermann J. Anti-tumour necrosis factor alpha treatment in chronic recurrent inflammation of the anterior segment of the eye in patients resistant to standard immunomodulatory treatment. Ann Rheum Dis. 2003;62:1243-1244.

33. Joseph A, Raj D, Dua HS, et al. Infliximab in the treatment of refractory posterior uveitis. Ophthalmology. 2003;110:1449-1453.
34. Muñoz-Fernández S, Hidalgo V, Fernández-Melón J, et al. Effect of infliximab on threatening panuveitis in Behcet's disease. Lancet. 2001;358:1644-1646.

35. Smith JR, Levinson RD, Holland GN, et al. Differential efficacy of tumor necrosis factor inhibition in the management of inflammatory eye disease and associated rheumatic disease. Arthritis Rheum. 2001;45: 252-257.

36. Sartani G, Silver PB, Rizzo LV, et al. Anti tumor necrosis factor alpha therapy suppresses the induction of experimental autoimmune uveoretinitis in mice by inhibiting antigen priming. Invest Ophthalmol Vis Sci. 1996;37:2211-2218.

37. Xia Q, Pang W, Pan H, et al. Effects of ghrelin on the proliferation and secretion of splenic T lymphocytes in mice. Regul Pept. 2004;122: 173-178.

38. Dixit VD, Taub DD. Ghrelin and immunity: a young player in an old field. Exp Gerontol. 2005;40:900-910.

39. Chang L, Zhao J, Yang J, et al. Therapeutic effects of ghrelin on endotoxic shock in rats. Eur J Pharmacol. 2003;473:171-176.

40. Korbonits M, Ciccarelli E, Ghigo E, et al. The growth hormone secretagogue receptor. Growth Horm IGF Res. 1999;9:93-99.

41. Pong SS, Chaung LY, Dean DC, et al. Identification of a new G-proteinlinked receptor for growth hormone secretagogues. Mol Endocrinol. 1996;10:57-61.

42. Rocha-Sousa A, Saraiva J, Henriques-Coelho T, et al. Ghrelin as a novel locally produced relaxing peptide of the iris sphincter and dilator muscles. Exp Eye Res. 2006;83:1179-1187.

43. Katsanos A, Dastiridou A, Georgoulias P, et al. Plasma and aqueous humour levels of ghrelin in open-angle glaucoma patients. Clin Experiment Ophthalmol. 2011;39:324-329.

44. Sehirli O, Sener E, Sener G, et al. Ghrelin improves burn induced multiple organ injury by depressing neutrophil infiltration and the release of pro inflammatory cytokines. Peptides. 2008;29:1231-1240.

45. Kasımay O, Işeri SO, Barlas A, et al. Ghrelin ameliorates pancreaticobiliary inflammation and associated remote organ injury in rats. Hepatol Res. 2006;36:11-19.

46. Erşahin M, Toklu HZ, Erzik C, et al. The antiinflammatory and neuroprotective effects of ghrelin in subarachnoid hemorrhage-induced oxidative brain damage in rats. $J$ Neurotrauma. 2010;27:1143-1155.
Drug Design, Development and Therapy

\section{Publish your work in this journal}

Drug Design, Development and Therapy is an international, peerreviewed open-access journal that spans the spectrum of drug design and development through to clinical applications. Clinical outcomes, patient safety, and programs for the development and effective, safe, and sustained use of medicines are a feature of the journal, which

\section{Dovepress}

has also been accepted for indexing on PubMed Central. The manuscript management system is completely online and includes a very quick and fair peer-review system, which is all easy to use. Visit http://www.dovepress.com/testimonials.php to read real quotes from published authors. 